\title{
Characterizations of 12-tungstophosporic acid metal salt nano particles synthesized by ultrasound
}

\author{
Elif Akbay ${ }^{1 *}$, Mert Can Ertaş ${ }^{2}$

\begin{abstract}
${ }^{1}$ Eskisehir Technical University, Dept. of Chemical Engineering, Eskişehir, 26470, Turkey, (ORCID ID 0000-0003-0323-7938), eodes@eskisehir.edu.tr
${ }^{2}$ Eskisehir Technical University, Dept. of Chemical Engineering, Eskişehir, 26470, Turkey, (ORCID ID 0000-0003-0963-3173), mertcanertas@gmail.com
\end{abstract}

(1st International Conference on Applied Engineering and Natural Sciences ICAENS 2021, November 1-3, 2021)

(DOI: 10.31590 /ejosat.1015865)

ATIF/REFERENCE: Akbay E., Ertaş, M.C. (2021). Characterizations of 12-tungstophosporic acid metal salt nano particles synthesized by ultrasound. European Journal of Science and Technology, (28), 1384-1387.

\begin{abstract}
A set of nano metal exchanged 12-tungtophosphoric acid salt $(\mathrm{M}=\mathrm{Fe}, \mathrm{Cr}, \mathrm{Ni}, \mathrm{Cu})$ was synthesized under ultrasonic irradiation in nanoscale. To thoroughly recognize the structure transformation induced by metal doping and morphologies of as-prepared M-TPA catalysts, a combination of XRF, XRD, SEM-EDX, $\mathrm{N}_{2}$ adsorption-BET, were employed. These analyzes indicate that the chemical structure and crystallinity of nano M-TPA remained unchanged while its morphology was found a different particle size according to the exchange metal.
\end{abstract}

Keywords: Nano, 12-tungstophosporic acid metal salt, ultrasonic irradiation.

\section{Ultrason yardımı ile sentezlenen 12-tungstofosforik asit metal tuzu nanoparçacıklarının karakterizasyonları}

$\ddot{O} \mathbf{z}$

Bir dizi nano metal değişimli 12-tungtofosforik asit tuzu $(\mathrm{M}=\mathrm{Fe}, \mathrm{Cr}, \mathrm{Ni}, \mathrm{Cu})$ ultrasonik 1şınlama altında nano ölçekte sentezlenmiştir. M-TPA katalizörlerinin metal dopingi ve morfolojilerinin neden olduğu yapı dönüşümünü tam olarak tanımak için XRF, XRD, SEMEDX, N2 adsorpsiyon-BET kombinasyonu ile karakterizasyon yapılmıştır. Bu analizler, nano M-TPA'nın kimyasal yapısının ve kristalliğinin değişmeden kaldığını, morfolojisinin metale göre farklı bir partikül boyutu bulunduğunu göstermektedir.

Anahtar Kelimeler: Nano, 12-tungstopphosporic asit metal tuzu, ultrasonik 1şınlama.

\footnotetext{
*Sorumlu Yazar: eodes@eskisehir.edu.tr
} 


\section{Introduction}

Nowadays, researches have been started on some acid catalysts that can replace traditional mineral acid catalysts for current environmental and economic reasons. In this context, heteropoly acids are called super acids with stronger acidity than $100 \%$ sulfuric acid $\left(\mathrm{H}_{2} \mathrm{SO}_{4}\right)$ (Misino, 2000). Heteropoly acids (HPAs), which possess ultra-strong acidity and unique Keggintype structure, show unique properties such as high stability, excellent solubility, environmentally benign, and so on. However, HPAs are also disadvantaged by low surface area $\left(<10 \mathrm{~m}^{2} / \mathrm{g}\right)$ and difficulties in catalyst recovery, which largely limit their practical industrial applications (Cavani,1998 and Okuhara et al,1996). Today, it is possible to produce catalysts with a very large active surface area with nano-sized particles, which are products of nanotechnology. Because the active surface area of the catalysts synthesized by nanoparticles is much wider than the larger particles (Gallezot et al, 2017). Therefore nanocatalysts, as heterogeneous catalysts, have emerged as sustainable alternatives to conventional catalysts because of its stability and high surface area (Polshettiwar et al, 2017). Nanocatalyst shows both homogeneous catalyst properties, characterized by high activity and selectivity because of high surface area due to the nanoscale, and heterogeneous catalyst properties, characterized by the easy separation from the reaction mixture because of their very lowresolution feature. Therefore, nanocatalysts synthesis methods have gained importance. One of them is sonochemical synthesis, which is an effective method under the irradiation of ultrasound in a solution that has been used to prepare various nanomaterials (Martos et al, 2001, and Abbasi et al, 2010). The use of ultrasound irradiation offers versatility, rapidity, and high reaction yields while being eco-friendly by employing water as a solvent (Pinjaria et al, 2013).

Heteropoly acids catalysts constitute an alternative for reactions, as they are characterized by well-defined structure, Bronsted acidity, high proton mobility, the ability to exchange electrons (Wang et al, 2017, Silva et al, 2020). As a heteropoly acid, 12-tungstophosphoric acid, $\mathrm{H}_{3} \mathrm{PW}_{12} \mathrm{O}_{40}$, is known as strong acid and it is considered within the class of superacid (Misino, 2000). One of the strategies to circumvent the above drawbacks is to by modifying HPAs with metal cations (e.g., Ag, Cs, Fe, Mn, $\mathrm{Fe}, \mathrm{Co}, \mathrm{Ni}, \mathrm{Cu}$ ) Lewis acid centers will be formed in addition to the Brønsted acid sites (Patel et al, 2014).

Herein, a series of metal ion-exchanged phosphotungstic acid (M-TPA) have been synthesized with the adopted metals included $(\mathrm{M}=\mathrm{Fe}, \mathrm{Cr}, \mathrm{Cu}, \mathrm{Ni})$. The physicochemical properties of the assynthesized M-TPA catalysts were characterized by a variety of different analytical and spectroscopic techniques such as XRD, XRF, SEM-EDX, and $\mathrm{N}_{2}$ adsorption.

\section{Material and Method}

All nano metal salts of 12-tungtophosphoric acid (M-TPA) were prepared according to the following method. To synthesize the catalysts, $0.05 \mathrm{M}$ aqueous solution containing a stoichiometric amount of metal salt was slowly added at a rate of about $1 \mathrm{ml} . \mathrm{min}^{-}$ 1 controlled by a flow meter to an aqueous solution of $0.04 \mathrm{M}$ heteropolyacid $\mathrm{H}_{3} \mathrm{PW}_{12} \mathrm{O}_{40} \cdot \mathrm{nH}_{2} \mathrm{O}(20 \mathrm{ml})$ at room temperature, under ultrasonic irradiation for $3 \mathrm{~h}$. The resultant suspension was dried at $333 \mathrm{~K}$ for 1 day and the solid was centrifuged and washed three times with methanol.
A multiwave ultrasonic generator (Bandelin Sonopuls Ultrasonic Homogenizers HD 3100; equipped with a generator, converter, converter cable, and ultrasound horn was used at a frequency of $20 \mathrm{kHz}$ for the ultrasound irradiation.

The crystallinity and the phase purity of the synthesized samples were analyzed by X-ray diffraction (XRD) patterns using X-ray diffractometer (RigakuRind XRD MiniFlex 300/600), and $\mathrm{Cu}-\mathrm{K} \alpha\left(1.54 \mathrm{~A}^{\circ}\right)$ radiation $(40 \mathrm{kV}-15 \mathrm{~mA})$. The scanning was done from $2 \Theta=70^{\circ}$ to $2 \Theta=5^{\circ}$ at a rate of $2^{\circ} \mathrm{min}^{-1}$.

The results from scanning electron microscopy (SEM) were obtained on an SEM-Benchtop tabletop microscope with $15 \mathrm{kV}$ accelerating voltage. X-ray fluorescence (XRF) analysis was carried out by using Rigaku ZSX Primus II.

The BET (Brunauer-Emmett-Taller) specific surface area was obtained from $\mathrm{N}_{2}$ adsorption desorption isotherm measured at $77 \mathrm{~K}$ in an automatic adsorption apparatus. Before measurement, samples were degassed at $100^{\circ} \mathrm{C}$ for about $2 \mathrm{hr}$..

\section{Results and Discussion}

In this work, ultrasonic irradiation was used in the synthesis of M-TPA (M: $\mathrm{Fe}, \mathrm{Cr}, \mathrm{Cu}, \mathrm{Ni})$ to achieve a unique catalyst in nanoscale. M-TPA was synthesized. The structure and morphology of all synthesized nanocatalysts were studied by XRD, XRF, BET, SEM, and $\mathrm{N}_{2}$ adsorption.

The results of the XRF analysis showed that W/Metal and $\mathrm{P} / \mathrm{Metal}$ ratios. The results are given in Table 1 .

Table 1. The result of XRF analysis of nano M-TPA

\begin{tabular}{|l|l|l|l|l|}
\hline \multirow{2}{*}{ Catalyst } & \multicolumn{2}{l|}{$\begin{array}{l}\text { Stoichiometri } \\
\text { c ratio }\end{array}$} & \multicolumn{2}{l|}{$\begin{array}{l}\text { Stoichiometric } \\
\text { ratio(calculated) }\end{array}$} \\
\cline { 2 - 5 } & $\mathbf{W} / \mathbf{M}$ & $\mathbf{P} / \mathbf{M}$ & $\mathbf{W} / \mathbf{M}$ & $\mathbf{P} / \mathbf{M}$ \\
\hline $\mathrm{FeP} W_{12} \mathrm{O}_{4 O}$ & 12 & 1 & 12.20 & 0.95 \\
\hline $\mathrm{CrP} W_{12} \mathrm{O}_{4 O}$ & 12 & 1 & 12.05 & 1.03 \\
\hline $\mathrm{Ni}_{3}\left(\mathrm{PW}_{12} \mathrm{O}_{4 O}\right)_{2}$ & 8 & 0.66 & 8.5 & 0.9 \\
\hline $\mathrm{Cu}_{3}\left(\mathrm{PW}_{12} \mathrm{O}_{40}\right)_{2}$ & 8 & 0.66 & 7 & 0.75 \\
\hline
\end{tabular}

As seen in Table 1, all synthesized nano-M-TPA were in agreement with the stoichiometric ratios of the M-TPA structure, indicating a successful formation of catalyst.

XRD analysis was performed for all synthesized M-TPAs given in Fig 1. 


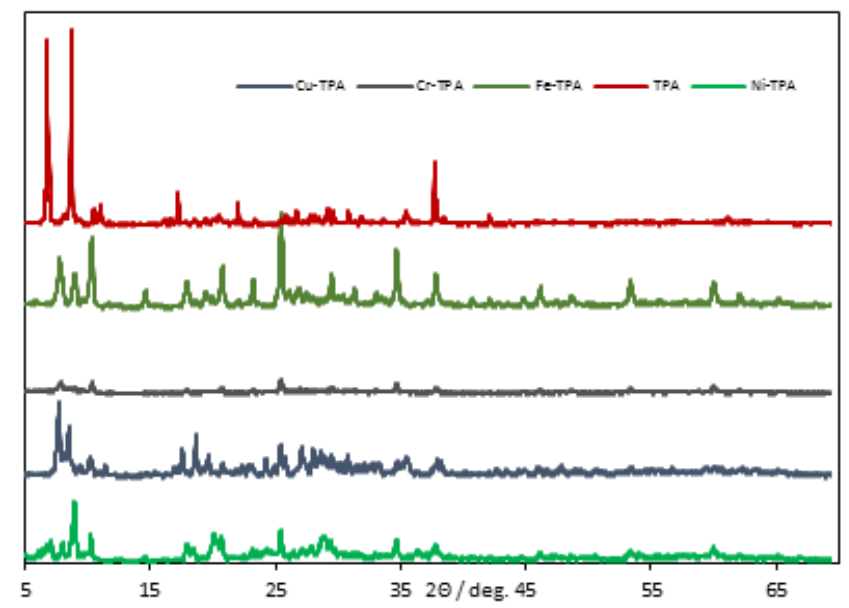

Fig. 1. XRD diagrams of nano M-TPA catalyst

As seen in Figure 1, the characteristic peaks of the Keggin anions in $\mathrm{H}_{3} \mathrm{PW}_{12} \mathrm{O}_{40}$ were observed at 8.10 and $37^{\circ}$. The same characteristic peaks of the Keggin structure were also observed in the synthesized $\mathrm{FePW}_{12} \mathrm{O}_{40}, \mathrm{CrPW}_{12} \mathrm{O}_{40} \quad \mathrm{Cu}_{3}\left(\mathrm{PW}_{12} \mathrm{O} 40\right)_{2}$, and $\mathrm{Ni}_{3}\left(\mathrm{PW}_{12} \mathrm{O}_{40}\right)_{2}$. with a slight shift toward higher $2 \Theta$ values was observed. These shifts show the interaction of metal on the structure of Keggin. Additionally, the characteristic peaks of the exchanged metal ( $\mathrm{Fe}, \mathrm{Cr}, \mathrm{Cu}, \mathrm{Ni}$ ) cations were also observed in the XRD patterns of the samples. In addition, there was a decrease in peak intensity due to metal interaction.

Table 2. Crystal sizes of nano M-TPA catalysts

\begin{tabular}{|l|c|c|l|}
\hline Catalysts & $\begin{array}{l}\text { Peak Degree } \\
\mathbf{2 \theta}\left(^{\circ}\right)\end{array}$ & $\begin{array}{l}\text { FWHM } \\
\mathbf{B}_{\text {size }} \mathbf{(}^{\circ}\end{array}$ & $\begin{array}{l}\text { Dp } \\
(\mathbf{n m})\end{array}$ \\
\hline $\mathrm{CrP}_{12} \mathrm{O}_{40}$ & 25.48 & 0.218 & 39.05 \\
\hline $\mathrm{FeP}_{12} \mathrm{O}_{40}$ & 25.48 & 0.244 & 34.89 \\
\hline $\mathrm{Cu}_{3}\left(\mathrm{P} W_{12} \mathrm{O}_{40}\right)_{2}$ & 7.74 & 0.261 & 31.89 \\
\hline $\mathrm{Ni}_{3}\left(\mathrm{PW}_{12} \mathrm{O}_{40}\right)_{2}$ & 8.96 & 0.320 & 26.03 \\
\hline
\end{tabular}

The crystal sizes of all synthesized nano M-TPAs were calculated using XRD data and the results are given in Table 2. Given in Table 2, the metal salts presented ranged from 26 (i.e., CuTPA) to $39 \mathrm{~nm}$ (i.e., FeTPA).

The morphology of the metal-exchanged TPA catalysts was also investigated by SEM shown in Fig. 3 .
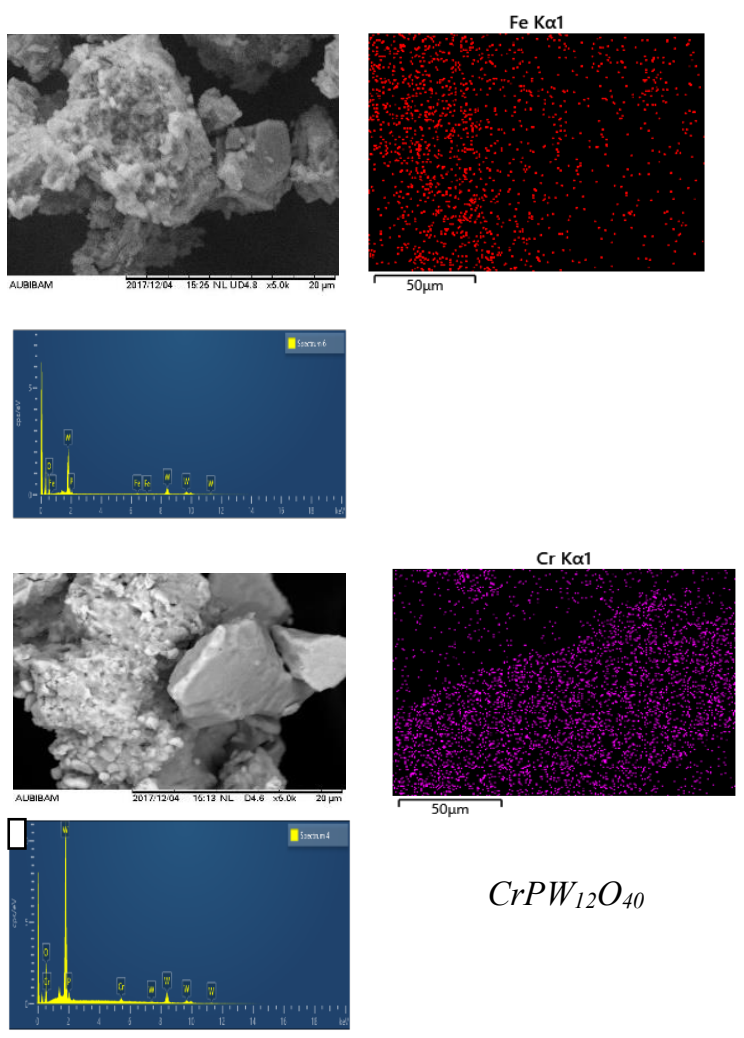

$\mathrm{CrPW}_{12} \mathrm{O}_{40}$
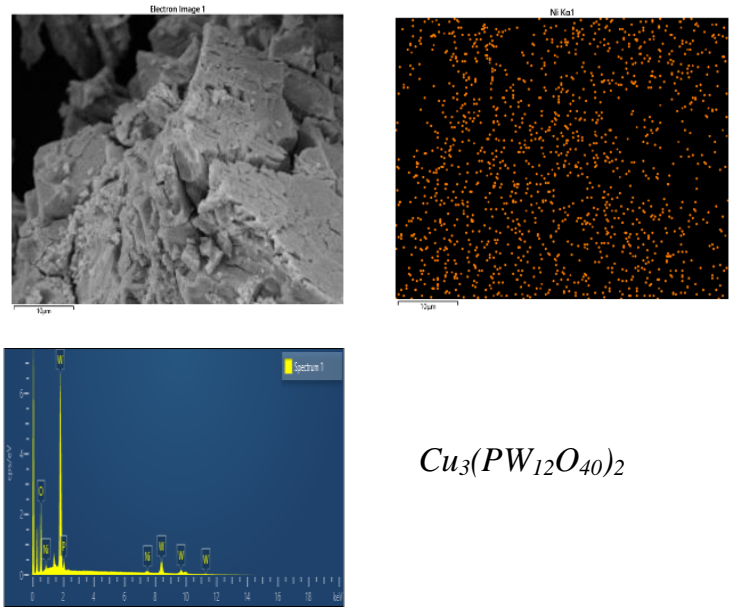

$\mathrm{Cu}_{3}\left(\mathrm{P} W_{12} \mathrm{O}_{40}\right)_{2}$
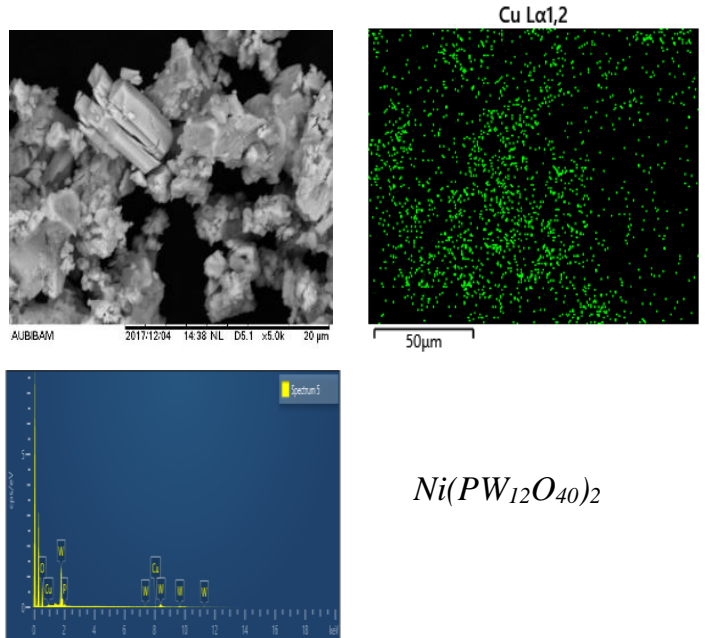

$\mathrm{Ni}\left(\mathrm{PW}_{12} \mathrm{O}_{40}\right)_{2}$

Fig 3. SEM, SEM-EDX mapping, and EDX spectra of nano $M-$ $T P A$ 
M-TPA are well-defined crystalline particles with the irregular shapes which is consistent with the literature.

The textural properties of pure TPA and metal exchanged TPA catalysts were investigated using $\mathrm{N}_{2}$ adsorption desorption analysis (Fig.4).

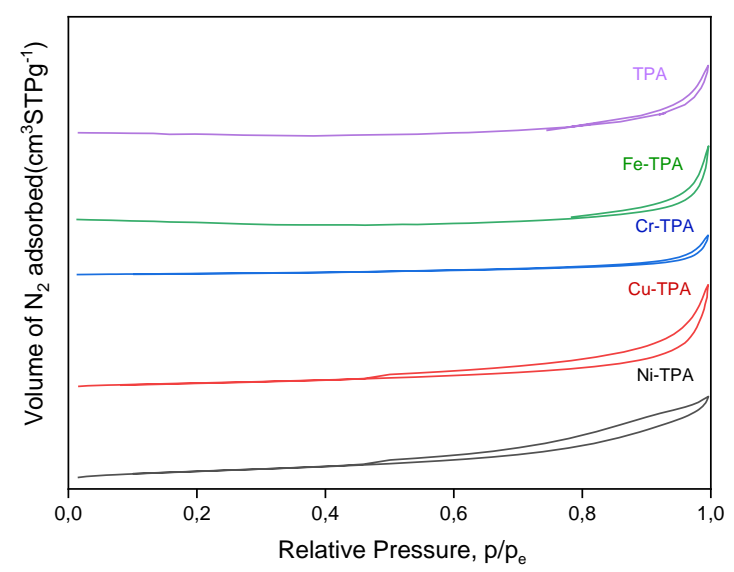

Fig.4. $\mathrm{N}_{2}$ adsorption isotherms of TPA and metal exchanged TPA

Average pore diameter. pore volume and BET surface area of these materials based on $\mathrm{N}_{2}$ adsorption analysis are given in Table 3.

Tablo 3. BET surface area, average pore diameter, pore volume of M-TPA catalysts on $\mathrm{N}_{2}$ adsorption analysis

\begin{tabular}{|c|c|c|c|c|c|}
\hline & $\begin{array}{l}\text { BET } \\
\text { Surfac } \\
\text { e Area } \\
\left(\mathrm{m}^{2} / \mathrm{g}\right)\end{array}$ & $\begin{array}{c}\text { Pore } \\
\text { Diamete } \\
\mathbf{r} \\
(\AA)\end{array}$ & $\begin{array}{c}\begin{array}{c}\text { Pore } \\
\text { Volume } \\
\left(\mathrm{cm}^{3} / \mathrm{g}\right.\end{array} \\
)\end{array}$ & $\begin{array}{c}\text { Pore } \\
\text { Volum } \\
\text { e } \\
\left(\mathrm{Meso}^{2}\right) \\
\left(\mathrm{cm}^{3} / \mathrm{g}\right) \\
\end{array}$ & $\begin{array}{c}\text { Pore } \\
\text { Volum } \\
\text { e } \\
\left(\mathrm{Macro}^{2}\right) \\
\left(\mathrm{cm}^{3} / \mathrm{g}\right)\end{array}$ \\
\hline$T P A$ & 5.91 & 57.27 & 0.102 & 0.0081 & 0.00 \\
\hline $\begin{array}{c}\mathrm{Fe}_{3}\left(\mathrm{PW}_{12} \mathrm{O}_{40}\right) \\
3\end{array}$ & 2.92 & 54.72 & 0.111 & 0.0031 & 0.0025 \\
\hline $\mathrm{Cr}_{3}\left(\mathrm{PW}_{12} \mathrm{O}_{40}\right)$ & 0.91 & 53.8 & 0.029 & 0.0017 & 0.0014 \\
\hline $\begin{array}{c}\mathrm{Cu}_{3}\left(\mathrm{PW}_{12} \mathrm{O}_{40}\right) \\
2\end{array}$ & 0.40 & 104.12 & 0.0022 & 0.0013 & 0.0009 \\
\hline $\begin{array}{c}\mathrm{Ni}_{3}\left(\mathrm{PW}_{12} \mathrm{O}_{40}\right) \\
2\end{array}$ & 0.04 & 72.24 & 0.0045 & 0.0025 & 0.0020 \\
\hline
\end{tabular}

According to IUPAC recommendations, the isotherms of the synthesized catalysts can be classified as type II as shown in Fig. 4. It is usually observed for non-porous or macroporous materials (Kong et al, 2016). The pore distribution of M-TPAs synthesized in nanoparticles has wide ranges. As can be seen from the pore volumes in the table. The macropore percentages of nano M-TPAs are high so, they have a highly nonporous structure and therefore their surface area is lower than TPA.

\section{Conclusions and Recommendations}

Nano metal exchanged 12-tungtophosphoric acid salt (M $=\mathrm{Fe}, \mathrm{Cr}, \mathrm{Ni}, \mathrm{Cu}$ ) were synthesized with ultrasonic and hydrothermal methods, one of the nanomaterial synthesis methods, in this work. All synthesized catalysts were characterized by XRF, XRD, SEM-EDX, and N2 adsorption analyzes. The characterization results show that the structure of M-TPA salts is synthesized as nanoparticles without deterioration.

\section{Acknowledge}

The authors gratefully acknowledge the financial support of the Scientific Research Projects of Eskisehir Technical University (No. 1709F521 and 1707F112).

\section{References}

Abbasi, A. Morsali (2010), Colloids Surf. A, vol 371 (1-3) pp. 113-118.

Cavani F.(1998), Heteropolycompound-based catalysts: A blend of acid and oxidizing properties. Catalysis Today, Vol. 41, Issues $1-3$.

Gallezot, P. (2007), Catalytic routes from renewables to fine chemicals. Catal. Today, Vol 121, Issues 1-2, pages 76-91.

Kong P.S., M.K. Aroua, W.M.A.W. Daud, H.V. Lee, P. Cognet, Y. Pérè s(2016), Catalytic role of solid acid catalysts in glycerol acetylation for the production of bio-additives: a review, RSC Advances, vol. 6 pp. 68885-68905.

Misono M. (2000), Heteropolyacids. Versatile green catalysts usable in a variety of reaction media. Pure Appl. Chem, Vol. 72, No. 7, pp 1305-1311.

Martos M. J. Morales. L. Sanchez. R. Ayouchi. D. Leinen. F. Martin. J.R. Ramos Barrado(2001). Electrochim. Acta 46 pp. 2939.

Okuhara, T. M. Mizuno, M. Misono (1996). Catalytic Chemistry of Heteropoly Compounds. Vol. 41, pp 113-252.

Patel C. M., M. Chakraborty, Z.V.P. Murthy(2014), Ultrason. Sonochem. vol 21 pp. 1100-1107.

Pinjaria D.V., K. Prasad, P.R. Gogatea, S.T. Mhaskeb, A.B. Pandita(2013), Chem. Eng. Process. vol 74 pp 178- 186.

Polshettiwar V. and R. S. Varma(2010), The Royal Society of Chemistry 12 743-754.

Silva M.J. da, A.A. Rodrigues(2020), Metal silicotungstate salts as catalysts in furfural oxidation reactions with hydrogen peroxide, Molecular Catalysis, vol 493111104.

Wang H. Liu L.-j, Gong S.-w.(2017), Esterification of oleic acid to biodiesel over a 12-phosphotungstic acid-based solid catalyst, Journal of Fuel Chemistry and Technology, vol 45 pp. 303-310. 